\title{
ARTÍCULOS
}

\section{Althusser y su lectura de Maquiavelo: ideología, república y democracia}

\author{
Althusser and his reading of Machiavelli: Ideology, Republic, and Democracy
}

\author{
Christian FAJARDO \\ Pontificia Universidad Javeriana, Bogotá \\ cjulian.fajardoc@javeriana.edu.co \\ ORCID iD: https://orcid.org/0000-0002-0580-0352
}

\begin{abstract}
Resumen: Este artículo busca problematizar la oposición entre democracia y república que está en el fundamento de la filosofía política. Siguiendo este horizonte, en primer lugar, se explora la razón que permite al pensamiento político, por un lado, reconocer el mérito de la democracia como acto fundacional de una república, pero, por el otro, desconocer su rol al interior de los cuerpos políticos ya fundados. En segundo lugar, y con la ayuda de la perspectiva de Louis Althusser, se sugiere que ese rol ambiguo y paradójico de la democracia se puede interpretar a la luz de una forma mistificadora de comprender la ideología que está presente en las filosofías políticas más hegemónicas. Finalmente se plantea abordar la relación entre democracia y cuerpo político desde la lectura que hace Althusser de Maquiavelo en su texto Maquiavelo y nosotros.
\end{abstract}

Palabras clave: Democracia; republicanismo; filosofía política; ideología; L. Althusser; N. Maquiavelo.

Cómo citar este artículo / Citation: Fajardo, Christian (2021) "Althusser y su lectura de Maquiavelo: ideología, república y democracia". Isegoría, 65: e05. https://doi.org/10.3989/isegoria.2021.65.05

ABSTRACT: This article seeks to problematise the opposition between democracy and republic that is at the foundation of political philosophy. Following this horizon, firstly, it explores the reason that allows political thought, on the one hand, to recognise the merit of democracy as the founding act of a republic, but, on the other, to ignore its role within already founded political bodies. Secondly, and with the help of Louis Althusser's perspective, it is suggested that this ambiguous and paradoxical role of democracy can be interpreted from a mystifying way of understanding ideology that is present in the most hegemonic political philosophies. Finally, it is proposed to approach the relationship between democracy and the body politic from Althusser's reading of Machiavelli in his text Machiavelli and Us.

Keywords: Democracy; Republicanism; Political philosophy; Ideology; L. Althusser; N. Machiavelli.

Recibido: 2 julio 2021. Aceptado: 15 julio 2021.

Copyright: (ㅇ 2021 CSIC. Este es un artículo de acceso abierto distribuido bajo los términos de la licencia de uso y distribución Creative Commons Reconocimiento 4.0 Internacional (CC BY 4.0). 


\section{INTRODUCCIÓN}

Siguiendo una de las indicaciones de Jacques Rancière que aparece en el cuarto capítulo de $L a$ mésentente (1995, pp. 95-131), es posible decir que en la filosofía política ha habido una rotunda oposición entre las prácticas democráticas y las idealizaciones republicanas ${ }^{1}$ que buscan instituir un orden social. Para esta tradición hegemónica del pensamiento político, la democracia es el conflicto irresoluble que se produce cuando los fundamentos de un mundo común son desestabilizados. La república, por el contrario, es el llamado a encontrar un orden institucional que lograría transformar el conflicto violento, que emerge de las rebeliones populares, en un agonismo argumentativo amparado por el derecho positivo. ${ }^{2}$ De acuerdo con esto, la república emerge cuando la 'democracia' se transforma en 'democracia representativa' o cuando el 'exceso democrático' del poder del demos es reemplazado por la politeia (república). Esto nos arroja a una paradoja que emerge en el corazón de la filosofía política: la democracia es plausible y útil porque siembra la preocupación por la búsqueda de un orden político justo. Sin embargo, ella no puede dar respuesta a esa búsqueda. La razón de esta incapacidad de la democracia consiste en que para crear un verdadero orden político es necesaria la moderación $\mathrm{y}$, por lo tanto, una forma de concebir la política que deje a un lado las pasiones excesivas que alimentan el poder del pueblo. De este modo, la república emergería en el seno de la democracia, pero distanciándose radicalmente de ella.

En este artículo, busco problematizar esta paradoja con la ayuda de la perspectiva de Louis Althusser. Desde mi punto de vista, su pensamiento político tardío ${ }^{3}$ nos ofrece unas indicaciones muy

\footnotetext{
En la teoría política contemporánea ha emergido una valiosa discusión sobre el republicanismo. Por ejemplo J. G. A. Pocock (2003), M. Abensour (1997) y P. Pettit (1999) han desarrollado, cada uno a su manera, la posibilidad de repensar el papel de la acción política y la democracia en los ordenamientos republicanos. Sin embargo, en este texto me centraré en un uso más general del republicanismo. Trataré de comprenderlo como un gesto ideológico al interior de la filosofía política como práctica intelectual. Para movilizar esta comprensión general del gesto republicano me apoyaré de J. Rancière $(1995,2006)$

2 No puedo dejar de hacer referencia al concepto de política deliberativa de Jürgen Habermas. En Facticidad y validez (2007), el filósofo de Frankfurt plantea la preponderancia del derecho para darle fin a los conflictos que emergen en el plano del mundo de la vida.

3 En este artículo prestaré especial atención a Sur la réproduction (2011), a Machiavel et nous (2009) y a Etre
}

plausibles para superar la paradoja antes enunciada, pues, como lo veremos, en el fundamento de dicha oposición se encuentra una mistificación ideológica que busca realizar la política a través de su más rotunda negación. Dicha problematización de los criterios ideológicos de la filosofía política me permitirá señalar que la democracia no es un conflicto irresoluble, sino la manifestación intempestiva de la política misma que reclama a su vez la posibilidad de instituir una estabilidad republicana que acoja el carácter conflictivo de la coexistencia humana.

Para desarrollar esta hipótesis, en primer lugar, pongo en evidencia la carga excesiva de la manifestación de la democracia, que se puede observar en los planteamientos del fundador de la filosofía política: Aristóteles. De acuerdo con esto, sostengo que la democracia no es el pasado primitivo de nuestras repúblicas, sino la actualización de un conflicto sobre lo común que es inconjurable. En segundo lugar, señalo que la oposición entre república y democracia proviene de una mistificación ideológica que busca realizar la política a través de su negación. Finalmente, me detengo en la posibilidad de abordar un pensamiento político que supere la mencionada mistificación, siguiendo la sugerencia de Althusser $(2003,2009)$ en Maquiavelo y nosotros. En esta última parte desarrollaré el concepto de republicanismo democrático.

\section{EL NACIMIENTO DE LA DEMOCRACIA: EL EXCESO DE SU MANIFESTACIÓN EN ARISTÓTELES Y EN LA FILOSOFÍA POLIITICA}

Para indagar en el problema o aprieto que trae consigo la democracia es necesario que comencemos por el comienzo, es decir, en la coyuntura histórica en la que emergió la democracia en el mundo occidental. Ubiquémonos en el siglo $\mathrm{V}$ antes de nuestra era, apoyándonos de Aristóteles (La constitución § 2-23) y de la sugerencia de Rancière sobre la emergencia del demos en la Antigüedad $(1995$, p. 27). De acuerdo con esto, me gustaría sostener que para los griegos la democracia no era el espacio de la deliberación en el ágora, como tampoco la denominada libertad que tenían los hombres libres para dedicarse a los asuntos públicos. La democracia es un fenómeno mucho más crítico y conflictivo que emerge no tanto de

marxiste en philosophie (2015). Esos tres textos tienen en común una comprensión de lo político en la que se problematiza la tradición de la filosofía política, tratando de encontrar una forma de reflexionar sobre lo político que no tiene como horizonte el buen gobierno, sino la prolongación de los espacios para el disenso y el conflicto. 
los hombres libres como de las clases subalternas o, en palabras de Aristóteles, de los pobres de la ciudad (La constitución, § 3; La política, 1291b). ${ }^{4}$ Para Aristóteles los pobres no son una casta de personas recluidas en el anonimato del mundo de la animalidad, que creen que su miseria proviene de un mandato de los dioses, sino un grupo supernumerario de la población que tiene cierta conciencia de clase, es decir, cierta conciencia de que no existe un fundamento religioso, trascendental o genético que les impida hacerse cargo de los asuntos comunes de la ciudad y, por lo tanto, de reconocerse y de hacerse reconocer como seres humanos, como auténticos animales hablantes. Sin embargo, ¿de dónde sale esta clase?; ¿qué condiciones se deben dar para que ciertas personas decidan dejar de reconocerse como una clase de individuos de segunda o tercera categoría?; ¿de dónde extrae el impulso un ciudadano que dice "preferiría no hacerlo", "preferiría no obedecer", aduciendo que su única propiedad es la libertad?

Para abordar esas preguntas me gustaría anticipar la postura de Althusser y también la de Rancière, uno de sus discípulos. Las miradas posmarxistas de estos dos pensadores nos dicen que un individuo nunca desobedece porque así lo desea su conciencia y su voluntad. Para esta tendencia del posmarxismo, que representan estos autores, un individuo desobedece cuando la historia se lo permite, cuando las circunstancias contingentes y conflictivas que vivimos se lo permiten. Veamos cómo ocurre esto de una manera puntual. Los pobres de la ciudad empezaron a predominar en la polis ateniense porque Solón en el siglo VI a. C. abolió la esclavitud por deudas con resultados retroactivos. Exactamente como ocurre con la culminación del proyecto Meiheim en Fight Club, en Atenas se condonaron todas las deudas de quienes habían caído en la esclavitud por no haberlas pagado. El resultado de esto fue evidente: quienes dejaron de ser esclavos no eran los sujetos que habían sido antes de caer en la esclavitud. Ya no eran ciudadanos con riquezas o con un relativo bienestar. Ellos eran, más bien, ciudadanos sin virtudes y sin riquezas. Lo único que los acreditaba como ciudadanos era su simple ciudadanía recién reco-

\footnotetext{
4 Aristóteles en La constitución de los atenienses, específicamente en el capítulo segundo consagrado a las reformas de Solón, dice que entre los ricos y los esclavos se encontraban "los restantes" que emergieron después de la abolición de la esclavitud por deudas. En La política, en el capítulo IV consagrado a los tipos de constituciones, el filósofo griego aduce que el partido de los pobres (los desposeídos) cuenta con la democracia, es decir, una forma de gobierno de quienes no tienen otro bien que la libertad.
}

nocida, que les otorgaba una única "propiedad": la libertad.

En ese contexto, de las filas de los pobres de la ciudad ateniense emerge Clístenes quien, después de la huida de los tiranos Cleómenes e Iságoras, instaura un gobierno popular. Este gobierno pone en marcha reformas estructurales que reordenan el uso del suelo en la ciudad: hace vivir a los ricos y a los pobres en lugares indiferenciados. También expropia a los oligarcas de sus apellidos. Los espacios territoriales que habitaban los ciudadanos fueron denominados "demos", es decir, "pueblos". Esta es la aparición de la democracia en el mundo occidental. En esa ocasión se cumplieron los requerimientos históricos para que una pluralidad de cuerpos pueda libremente llevar hasta las últimas consecuencias la ausencia de fundamento que sustenta toda autoridad.

Esta bella historia de la aparición de los desposeídos de la ciudad desde la constitución de Solón hasta las reformas de Clístenes es el antecedente de la filosofía política, es decir, del encuentro entre la democracia y la intervención de los sabios para darle orden a ese conflicto democrático. El capítulo IV de La Política ofrece unas luces muy interesantes sobre cómo el sabio y filósofo Aristóteles se imaginó la verdadera solución ante la aparición de la democracia. Para el autor de la La política, existen dos formas de gobierno: la de los ricos y la de los pobres; la oligarquía y la democracia. La pretensión que busca pensar en la aristocracia como una tercera forma de gobierno descuida que "la educación y la nobleza acompañan preferiblemente a los más ricos" (La política, 1293b). En esa medida, el gobierno de los mejores siempre coincide con el de los ricos, en cambio el gobierno de los desposeídos, que solo tienen la libertad, coincide con el de los pobres. ${ }^{5}$ Sin embargo, a juicio de Aristóteles, cada una de estas formas tiene sus limitaciones: mientras la oligarquía acredita solo a los ricos para el ejercicio de las magistraturas, la democracia promueve el gobierno de los demagogos que gobiernan no con la ley, sino con decretos que emergen de las ansias de los muchos (La política, 1292a). Aristóteles, a diferencia de Platón, ${ }^{6}$ considera que la república

\footnotetext{
5 Para Aristóteles las monarquías, en último término, no son regímenes políticos porque son cercanos a las tiranías y, por lo tanto, son las formas de organización de lo común menos constitucionales.

6 Para muchos comentadores de la obra de Platón, la República no es tanto una forma de gobierno mixta sino una oligarquía en la que gobiernan los más cercanos a la sabiduría: los filósofos (Rancière, 2014).
} 
es una forma de gobierno mixta en la que aparece lo mejor de cada una de esas formas políticas de gobierno. Por ejemplo, esa combinación permite, por un lado, que no sea la renta la que acredite a un ciudadano como magistrado, sino el resultado de una elección en la que participan todos los ciudadanos; por el otro lado, que no sea la muchedumbre la que ejerza el poder, sino unos pocos que han logrado conseguir las magistraturas. La república es entonces la idealización filosófica, que busca reemplazar la naciente lucha de clases en el mundo occidental por un escenario en el que las clases sociales se enfrentarían de una manera agonística, es decir, de una manera en la que se establezca un acuerdo sobre la confrontación política. Por eso, la república es un punto medio que tiene la siguiente eficacia: "en una república bien mezclada debe parecer que existen a la vez ambos regímenes [la democracia y la oligarquía] y ninguno de ellos [...] ninguna de las partes querría otro régimen" (La política, 1294b). Esta preocupación se extiende al pensamiento político contemporáneo. Chantal Mouffe en su reciente libro Agonística (2014) apunta hacia esa dirección republicana de Aristóteles, al creer en la posibilidad de sublimar el antagonismo social y transformarlo en un agonismo que pacifique las luchas entre ricos y pobres, entre amigos y enemigos. Para Mouffe, la verdadera política republicana, comienza cuando se deja de luchar por los meros asuntos de clase para construir un escenario inteligente en el que se disputan comprensiones simbólicas (hegemónicas) del mundo.

Lo anterior nos permite decir que la democracia hace posible el conflicto político. Sin embargo, la salida a ese conflicto no la trae consigo la democracia, sino la moderación republicana que nace con las idealizaciones de la filosofía política. Por esa razón, para Aristóteles la democracia no permite estabilizar la vida en común porque trae consigo la arbitrariedad y la excepción a la norma republicana. Con este rechazo a la democracia, Aristóteles rinde tributo a Platón. Recordemos que, para este último, un gobierno que realmente propenda por la justicia debe luchar en contra de la democracia, es decir, en contra del poder de la presunta muchedumbre enardecida que confunde la justicia con la venganza, la igualdad con la equidad y el bien con el mal. Sin embargo, como lo aprecia Rancière (1995, pp. 34-35), el rechazo a la democracia es en realidad el rechazo al escándalo de la práctica política misma. Lo que rechaza la filosofía política es la idea de que los asuntos comunes estén en las manos de una clase que desclasifica, de una clase que no es una clase o de una parte de la sociedad que no tiene otra propiedad sino la libertad. El escándalo de la democracia estriba entonces en que el demos no solo desobedece al orden social, sino también pone en entredicho el orden simbólico que sustenta las relaciones de mando y de obediencia. El gesto o la violencia de la filosofía política consiste en equiparar ese escándalo con la ceguera y la incapacidad del pueblo. Sin embargo, la paradoja es clara y contundente: sin esa presunta ceguera de la aparición estrepitosa del demos jamás se hubiese producido una reflexión sobre el gobierno justo. La filosofía política emerge entonces cuando se plantea que los pobres de la ciudad no pueden realizar sus propias idealizaciones, de ahí que tengan que acudir siempre a un mediador. En la historia de Occidente han aparecido diversas figuras como la del filósofo, la del revolucionario profesional o la del gestor de lo común, que, en los días de hoy, es aquel o aquella que cuenta con las herramientas técnico-económicas para darle un uso racional y eficiente a la gestión pública.

Hannah Arendt en Sobre la revolución (2013) y Maurice Merleau-Ponty en Las aventuras de la dialéctica (2014) ponen en evidencia el papel que han jugado los mediadores en las revoluciones modernas. Del mismo modo que los filósofos políticos de la Antigüedad, los revolucionarios profesionales le otorgaron un rumbo moderado a los reclamos populares que buscaban sepultar el Ancien Régime. Los diseñadores del orden constitucional y los expertos de la gestión del gobierno se vuelven los mediadores de la estrepitosa muchedumbre que pide una transformación. La razón de esta intervención consiste en que esa muchedumbre no tiene la capacidad de realizar esa transformación, porque viven no solo en la precariedad sino en el eterno lamento de no ser vistos, de no tener lo que para el político es fundamental: la capacidad de aparecer y hacerse visibles. En esa dirección apuntan las palabras del republicano John Adams, uno de los padres fundadores de la república estadounidense: "La conciencia del pobre es limpia; sin embargo, se siente avergonzado [...] Se siente apartado de los demás, andando a tientas en la oscuridad. La humanidad no se ocupa de él [...] lo que ocurre es que nadie repara en él" (citado por Arendt, 2013, p. 108). Estas palabras de Adams inquietan a Arendt porque allí se pone en juego la paradoja de la democracia antes anunciada: el malestar de la no-aparición de los pobres en la esfera pública no puede ser percibido por ellos porque, en último término, la lucha por 
la visibilidad no tiene sentido (Paredes, 2014, p. 173). El pensamiento republicano que se extiende a una vertiente hegemónica de la filosofía política advierte entonces de la incapacidad de la democracia de realizar un orden político justo.

Todo esto nos obliga a decir que para la tradición que nace con la filosofía política se produce una oposición entre prácticas democráticas e idealizaciones republicanas. Estas últimas aseguran que la desobediencia del pueblo insumiso adquiera un sentido, un orden o, mejor aún, una moderación. El fundador de la filosofía política moderna, Thomas Hobbes, también manifiesta esta misma oposición entre república y democracia. Sin embargo, él no se refiere al mal que produce la democracia, sino a la contingencia radical del estado de naturaleza. Tampoco se refiere a la necesidad de asegurar un espacio para que deliberen los filósofos, pero sí piensa que debe haber un ordenamiento jurídico que dé la potestad absoluta al soberano para decidir sobre los asuntos comunes. Esto nos permite decir que la filosofía política antigua, el pensamiento político moderno y la ciencia política contemporánea tienen, en términos muy generales, un presupuesto ideológico que se puede enunciar de la siguiente manera: la única manera de poner en orden al conflicto democrático es traicionando a la democracia. Ya no es Dios, ni la tradición los que vuelven a ubicar a los pobres en su lugar, sino la mudez y el vacío del argumento autoritario que decide sobre lo justo y lo injusto. Schmitt (2004, pp. 25-27) advierte sobre este vacío de nuestras repúblicas y de nuestros Estados, al sugerir que en último término todo orden normativo descansa sobre la excepción. En el siguiente apartado, me gustaría simplemente encontrar una alternativa desde una perspectiva posmarxista a este dilema ideológico al que nos ha llevado la filosofía política. Por eso me gustaría desarrollar tres preguntas: ¿Hasta qué punto hay un anclaje ideológico en la oposición entre democracia y república?; ¿es posible hablar de un republicanismo democrático, es decir, de una república que no traicione el poder insurgente del demos?; ¿es posible transformar los momentos efímeros de la democracia en duración, es decir, en una temporalidad que prolongue la emergencia del conflicto democrático a través de lo que hemos denominado "leyes"?

\section{LA MISTIFICACIÓN IDEOLÓGICA}

La mirada posmarxista del filósofo Louis Althusser nos puede ayudar a encontrar que la oposición entre república y democracia tiene como funda- mento cierta comprensión ideológica de la vida en común. En De l'ideologie, el filósofo francés es enfático en mostrar que la filosofía política emerge en el corazón de la lucha de clases (2011,p.48) o, como lo hemos venido abordando en este texto, en el conflicto radical que instituyen los pobres de la ciudad. A partir de ese momento, la filosofía, en su vertiente más predominante, comienza a defender unos intereses de clase, aduciendo que, por regla general, los pobres no se pueden hacer cargo de la gestión de lo común. Esta regla general, en muchos casos implícita en las filosofías políticas, tiene como eficacia ideológica la idea de que los desposeídos no tienen la capacidad de salir del conflicto que ellos mismos instituyen. De acuerdo con esto, la filosofía cumple la siguiente tarea de conversión ideológica: hace que los pobres de la ciudad caigan en la cuenta de que son incapaces de realizar su propia reivindicación, es decir, les hace ser conscientes de que la única manera de acabar con la injusticia de la exclusión es, precisamente, reproduciendo la exclusión que ellos mismos denuncian. Los desposeídos, debido al lugar desfavorable que ocupan en el orden social, no tienen el tiempo libre, ni las capacidades de participar en los asuntos públicos. Como ya lo ha hecho notar Rancière (1995), esa es la razón del porqué Aristóteles en el libro IV de La política prefiere la democracia campesina, pues en ese régimen solo participan quienes tienen tiempo libre (La política, 1292b). Esto nos permite decir que la filosofía política está atravesada por un conjunto de prácticas ideológicas que buscan hacer creer al pueblo que sus pasiones desbordadas le impiden participar en la política con la mesura que se requiere. Platón lo sabía muy bien cuando decía que "hay que enseñar al 'pueblo', desde su infancia, las 'mentiras nobles' que lo 'hacen marchar' y, además, hace falta enseñarlas de tal manera que el pueblo las crea" (Althusser 2011, p. 213, traducción propia). La filosofía se vuelve una práctica ideológica que crea un tejido sensible que busca asegurar una dominación simbólica de clase, haciendo proporcional la exclusión con la incapacidad; el lugar desfavorecido de los pobres con la incapacidad objetiva de dedicarse a la práctica política.

Sin embargo, no se trata de que los filósofos engañen al pueblo, ni de que la ideología produzca un velo de ignorancia que no les permite ver a los pobres que sus condiciones de vida son precarias o que son explotados por un tercero que los despoja del plusvalor en las jornadas laborales. Todo lo contrario: esta distribución ideológica de 
lo sensible trata de hacer evidente al menos dos cosas: por un lado, que la pobreza es una condición de la que no se puede escapar (solo para unos pocos está predestinado el camino del ascenso social); por el otro lado, que el lugar desfavorecido que ocupan los pobres en el orden social les impide ser lo suficientemente racionales, de ahí que necesiten siempre de un mediador para acceder a su libertad política. En esa medida, como lo aprecia Slavoj Žižek (2018), la ideología no oculta, sino que hace ver con cierta naturalidad que la realidad, por brutal que parezca, no puede ser de otra manera. La ideología tiene eficacia cuando, a pesar de que somos conscientes de las injusticias del mundo, no podemos dejar de reproducirlas. De acuerdo con esto, la ideología no es un mundo ilusorio que nos hace ver la realidad de una manera distorsionada, sino el presupuesto que nos hace ver con naturalidad y con certeza que existe una realidad que nos determina, a pesar de lo brutal y abyecta que pueda llegar a ser para nosotros. Ese es precisamente el fundamento de la oposición entre democracia y república: nos dice que existe una realidad que, a pesar de todo, termina excluyendo a los pobres de la ciudad de la participación en la política. Esa realidad le hace ver al pueblo que sus ilusiones (un mundo más justo) no son más que ilusiones, que su deber es acoplarse a la realidad. Y para que se produzca ese acople, solo puede contribuir con lo mejor que puede aportar: su propia exclusión de la gestión de lo común. Ahora bien ¿Cómo realizar una crítica a esta resignación republicana?

Para abordar ese interrogante, me gustaría poner en consideración que la ideología está atravesada por unos repartos de nuestra sensibilidad que hacen aparecer una realidad compartida de determinada manera. En esa medida, hay que dejar a un lado el uso peyorativo del concepto de ideología, muy vinculado con los textos de juventud de Marx como La ideología alemana (2010). Recordemos que en ese texto el pensador alemán busca definir a la ideología como una representación que distorsiona la realidad. En cambio, acá estamos hablando de un uso mucho más neutral, pues la ideología está formada por los criterios que guían nuestra experiencia compartida. Volviendo una vez más a Althusser, diremos que la ideología es una “"representación' imaginaria de las relaciones imaginarias de los individuos con sus condiciones reales de existencia" (Althusser, 2011, p. 214). De acuerdo con esas palabras, habría que diferenciar la "representación imaginaria" de las "relaciones imaginarias". La primera es una condición de po- sibilidad de la segunda, pues la representación imaginaria brinda los criterios para que una determinada experiencia de la realidad tenga lugar. En otras palabras, todos los conceptos que nos permiten relacionarnos con nuestras condiciones de existencia (relaciones imaginarias) están precedidos por un reparto de nuestra sensibilidad (representación imaginaria). Con esto quiero decir que cuando una comunidad habla o se refiere a la "justicia", lo hace en virtud de un reparto previo que hace posible un consenso sobre lo "justo". Esos criterios trascendentales, en el sentido kantiano del término, ${ }^{7}$ no son equivalentes a la experiencia sino a los criterios que hacen posible toda experiencia. En esa medida, lo que habría que poner en cuestión no son las prácticas que excluyen a los pobres de la ciudad de los asuntos comunes, sino a las condiciones de posibilidad que permiten que esas prácticas de exclusión tengan lugar. Como lo he apuntado, esas condiciones son ideológicas porque responden a repartos específicos de nuestra sensibilidad.

Ahora bien, con la ayuda del epílogo a la segunda edición de El Capital de Karl Marx, me gustaría hacer énfasis en dos modos de comprender esas distribuciones ideológicas de lo sensible. En ese texto de 1873, el filósofo alemán dice que, para comprender su intención en El Capital, lo importante no es el método dialéctico en sí mismo, sino la forma de comprender la dialéctica. Veamos sus palabras:

En su forma mistificada, la dialéctica estuvo en boga en Alemania, porque parecía glorificar lo existente. En su figura racional, es escándalo y abominación para la burguesía y sus portadores doctrinarios porque en la intelección positiva de lo existente incluye también, al propio tiempo, la inteligencia de su negación [Verständniß seiner Negation], de su forzosa ruina [nothwendigen Untergangs]; porque concibe toda forma desarrollada en el fluir de su movimiento [Flusse der Bewegung], y por tanto sin perder de vista su lado perecedero; porque nada la hace retroceder y es, por esencia, crítica y revolucionaria (Marx, 2017, p. 57, 1987, p. 709; cursivas propias y traducción modificada).

\footnotetext{
Kant en La crítica de la razón pura hace una distinción entre sensibilidad y sensación. Si interpretamos análogamente a Althusser y a Kant, diremos que es la sensibilidad la que hace posible toda sensación (Empfindung), porque cuando hablamos de la sensibilidad (Sinnlichkeit), a juicio de Kant, estamos refiriéndonos "no tanto a la representación que tenemos de las cosas, sino a la capacidad de recibir representaciones gracias a la manera como somos afectados por objetos" (CRP, p. B34).
} 
En esa cita se enuncian dos formas de comprender la dialéctica, de las que me gustaría derivar dos formas de comprender la ideología. ${ }^{8} \mathrm{La}$ más hegemónica es la que él llama forma mistificada (mystificirten Form). Según esta forma, todo lo existente tiene como fundamento la necesidad $\mathrm{y}$, por lo tanto, busca glorificar (verklären) lo existente; por otro lado, se encuentra la dialéctica en su forma racional (In ihrer rationellen Gestalt). En esta lo existente además de traer consigo una intelección positiva (positiven Verständniß), trae también la inteligencia de la negación (Verständniß seiner Negation), mostrando que todo lo existente está condenado a transformarse e incluso desaparecer porque en la base de su fundamento no se encuentra la necesidad, sino el fluir del movimiento (Flusse der Bewegung). Ahora bien, mi hipótesis consiste en que la práctica ideológica que predomina en la filosofía política o en la oposición entre república y democracia, es la mistificación ideológica porque para la filosofía política hay una necesidad de ordenar el desorden democrático cuando la filosofía política proclama implícitamente la necesidad de darle orden y horizonte al desorden desatado por la democracia. Pero ¿cómo comprender lo necesario y la necesidad que busca reordenar el mundo convulsionado por la manifestación de la democracia?

Para comprender el carácter conceptual de la necesidad que está en la base de las palabras de Marx, empecemos por referirnos a lo que no es necesario, es decir, a lo contingente. Pensemos en el padre autoritario. Aquel que le da órdenes a su hija de no salir un viernes en la noche. La hija debe acatar las órdenes de su padre porque es su padre. Sin embargo, la hija obedece a pesar de saber que su padre no solo es un autócrata, sino un machista que sí le otorga permisos a su hijo varón. Ella sabe que, por puras contingencias históricas, los hombres han tenido un lugar privilegiado en el mundo occidental, pero aun así obedece. Sabe también que por razones circunstanciales su familia ha logrado posicionarse en una clase media que le ha permitido pagar los estudios a sus hijos y tener una casa propia. Parece que ella obedece por la necesidad, sin embargo, no es así. La hija con conciencia de clase y con conciencia de género obedece no porque considera necesaria la autoridad de su padre, sino porque no tiene medios materiales para rebelarse, para desobedecer o, mejor aún, no existen las circunstancias materiales para desobedecer. Ella

\footnotetext{
8 En otro lugar he desarrollado el pensamiento de la contingencia que desarrolla Karl Marx en El Capital. Ver Fajardo, 2020, 2021.
}

opta por obedecer no porque su padre es la necesaria autoridad, sino por la pura facticidad de las jerarquías que se tejen en las relaciones sociales. De la misma manera, un trabajador sindicalizado obedece a su patrón. La relación de subordinación para él no es necesaria sino circunstancial, se cree que, en algún momento, se puede revertir.

Ahora bien, pensemos en otra relación en la que un padre ejerce poder sobre su hija. En esta ocasión pasa exactamente lo mismo. El padre no deja salir a su hija. Sin embargo, para la configuración ideológica de esta hija, su padre es una autoridad necesaria. Ella obedece a su padre descartando el carácter circunstancial y transitorio de su autoridad. Ella cree que su padre es la encarnación de la Ley. Žižek, retomando El Proceso de Kafka, nos dice que, para estos casos, "no hay que aceptar la Ley como verdad, sino únicamente como necesaria -el hecho de que su autoridad carece de verdad-" (Žižek, 2018, p. 67). De acuerdo con esto, se puede decir que la necesidad es una forma de configurar nuestras prácticas ideológicas en la cual las relaciones de autoridad aparecen como ineludibles, a pesar de que no haya un fundamento evidente que sustente esa autoridad. Podemos darle muchos nombres a este fundamento vacío y carente de toda verdad: masculinidad, Dios, Justicia, etc. Por esa razón, la ideología no es una explicación que hace que los sujetos interioricen el patriarcado o el capitalismo, sino un tejido sensible que permite la emergencia de la necesidad de la valorización del capital o del poder masculino. La necesidad no brinda explicaciones, sino enunciados tautológicos como "la ley es la ley", "el poder masculino es el poder masculino" o "el dinero es el dinero". Retomando una vez más los postulados de Žižek, la ideología mistificadora es, en realidad, una fantasía ideológica. En ella no se oculta la verdadera explicación de la autoridad, ni tampoco las verdaderas causas de la opresión social. Lo que oculta la ideología mistificadora es la contingencia sobre la que se instituye toda ley, todo relato y toda autoridad. En esa medida, la mistificación ideológica reduce a su máximo nivel la capacidad intelectual de la mediatización, es decir, la capacidad de poner al descubierto que detrás de toda autoridad, de toda identidad, de todo proceso de subjetivación hay, realmente, una fluir del movimiento que carece de sentido, de arkhè, o de explicación. Ahora bien, esta idea de mistificación no crea ilusiones sobre el fundamento, tampoco oculta que unos tengan mucho y otros nada. Lo que oculta es la contingencia del orden social al reemplazarla por la 
necesidad del orden social. Ese es precisamente el argumento de Platón que replican los gestores contemporáneos de los asuntos públicos. El orden y la armonía social son preferibles porque es necesario que así lo prefiramos. Y para eso nos tenemos que convencer, por un lado, de que quienes mandan lo hacen debido a una necesidad que no requiere explicación; por el otro, de que quienes padecen las peores condiciones socioeconómicas necesariamente están en esa condición por la necesidad que plantean, por ejemplo, las externalidades del mercado.

Ahora bien, retomando la pregunta por la condición de posibilidad de la oposición entre república y democracia, considero que la filosofía política es una práctica que tiene como fundamento la mistificación ideológica. Esto ocurre cuando se plantea la necesidad de salvar a la democracia de su autodestrucción a través de la mesura republicana. Como lo he reiterado, el fundamento de esta práctica ideológica es la búsqueda del orden, de la armonía social y de la estabilización de las expectativas del comportamiento de los seres humanos. Siguiendo este carácter ideológico de comprender lo político, Quentin Skinner en El nacimiento del Estado (2003, p. 62) es enfático en mostrar que el carácter republicano de la teoría del Estado de Hobbes estriba en mostrar que el pueblo adquiere cierta universalidad cuando su poder puede llegar a ser atribuido a un soberano. Sin esa mediación de la soberanía, el pueblo no llegaría a habitar una verdadera república. Sin embargo, ¿por qué, en ese caso, se prefiere la ausencia de conflicto social?; ¿qué hace que el pensamiento republicano de Skinner prefiera la universalidad de un pueblo que atribuye su libertad a través de la soberanía, en lugar del conflicto que emerge cuando el pueblo reclama una universalidad sin atribuirla a la autorización de un tercero?

Un joven republicano respondería: el orden es preferible al conflicto porque así podemos armonizar y estabilizar nuestras expectativas del comportamiento. Sin embargo, la pregunta sigue sin responder: ¿Por qué se espera tanto de la estabilización de las expectativas del comportamiento? La razón de esta evasión no es teórica, ni filosófica, sino ideológica. Se cree en el orden porque allí se enuncia lo justo y lo injusto, lo político y lo no político y, asimismo, el lugar que debe ocupar cada persona en un mundo común para que esas distinciones tengan eficacia. El republicanismo que impregna a la filosofía política debe traicionar a la democracia porque ella impide el cierre del conflicto y, para llevar a cabo esto, transforma la democracia en democracia representativa; la exigencia radical por la igualdad en la equidad; el respeto a una idea revolucionaria en el respeto por el imperio de la ley. De acuerdo con esto, podemos decir que la mistificación ideológica es, como aduce Althusser (2011, p. 218), una representación ideológica de la ideología, es decir, una ideología que es sumisa a lógica de la necesidad porque hace efectivas, en nuestras prácticas materiales, enunciados que son tautológicos: esta ley es una ley; lo justo es lo justo, la autoridad patriarcal es la autoridad patriarcal; la razón es la razón; la justicia del orden es la justicia del orden. Esta sutura entre un sujeto que es idéntico al predicado permite que la arbitrariedad que conecta la ley con la ley sea eliminada no tanto en nuestra conciencia, sino en nuestras prácticas cotidianas. Sabemos que el dinero es representado por un objeto que no es, propiamente hablando, el dinero y, sin embargo, hacemos de cuenta que un papel con el sello de un banco emisor cuente como dinero. Sabemos que un juez es una persona como nosotros que, en ciertos momentos, encarna la autoridad de la ley. El mismo Žižek (2018, p. 81) nos dice que esta forma ideológica "designa una totalidad que borra las huellas de su propia imposibilidad". En otras palabras, la mistificación ideológica es la práctica que hace que un juego de idealidades y de idealizaciones produzcan prácticas que tienen como horizonte la presunta armonía social y, por lo tanto, el fin de los conflictos democráticos para dar paso a una sociedad de ciudadanos iguales ante la ley; de ciudadanos que deben ser producidos por aparatos educativos que los hagan aceptar el imperio de la civilidad y de las buenas costumbres, haciendo coincidir las leyes con sus formas de ser; los imaginarios comunes con sus prácticas cotidianas. De acuerdo con esto, en el tercer apartado que viene a continuación, me gustaría sugerir algunas ideas sobre cómo pensar el conflicto entre república y democracia que no se resuelva a través de lo que he venido llamando mistificación ideológica. Para esto me gustaría traer muy brevemente la relectura que propone Althusser de Maquiavelo en su texto Maquiavelo y nosotros.

\section{REPÚBLICA Y DEMOCRACIA}

A juicio de Althusser, Maquiavelo propone oponer a la mistificación ideológica de la filosofía política una ideología de la contingencia o dicho, en términos de Marx, una ideología de la racionalización (Marx la llama dialéctica de la racionalización). El objetivo de esta mirada maquiaveliana es, a juicio Althusser, concebir la "unidad" de una 
sociedad a través de una estructura jurídica que se apoye no tanto en el acuerdo unánime hacia la resolución de los conflictos humanos, sino en la lucha de clases o en el conflicto que trae la lucha de clases. En esa medida, la apuesta de Althusser consiste en reflexionar sobre un pensamiento republicano que tenga como horizonte no tanto la resolución de los conflictos de clases, como la facilitación para que la lucha de clases tenga lugar. El pensador francés encuentra en Maquiavelo una posible respuesta a la búsqueda de un pensamiento republicano que escape de la trampa ideológica de la mistificación, ya que el autor de El Príncipe busca concebir la unidad de la nación italiana de su tiempo, teniendo como fundamento no tanto la unión de los estamentos, sino la explicitación de las diferencias de clase y, por lo tanto, de sus concepciones de mundo. La filosofía política de Maquiavelo problematiza entonces la práctica ideológica de la mistificación señalando la posibilidad de pensar en un más allá de la oposición dicotómica entre una sociedad fracturada por la lucha de clases y una sociedad de ciudadanos indiferenciados, entre el conflicto democrático y la república del imperio de la ley. Sin embargo ¿Esto quiere decir que Maquiavelo es un pensador excéntrico como lo llegó a ser Jefferson al decir que cada generación debería tener el derecho a realizar una revolución para derrocar las injustas estructuras jurídicas que les legaron las anteriores generaciones?

Desde la perspectiva de Althusser, a Maquiavelo le interesa la construcción de la unidad nacional. Sin embargo, esta unidad no es la de la estabilización de las expectativas del comportamiento de los ciudadanos, como tampoco es la glorificación de la lucha de clases como una guerra irresoluble. La construcción de unidad nacional en Maquiavelo debe estar construida sobre dos tesis filosóficas que aparecen en los Discursos sobre la primera Década de Tito Livio, que Althusser decanta con especial genialidad.

La primera de estas tesis es que el mundo es inmutable y con esto el propio Maquiavelo dice lo siguiente: "Cualquiera que compare el presente con el pasado verá que todas las ciudades, todos los pueblos, han estado siempre y lo están aún animados por los mismos deseos, por las mismas pasiones [...]. Se ven regresar en todos los tiempos los mismos males y las mismas revoluciones" (Althusser, 2004, p. 70). La segunda tesis es la siguiente: "Todas las cosas de la tierra están en un movimiento perpetuo, y no pueden permanecer fijas. Esta inestabilidad las lleva a ascender o a caer. La necesidad empuja frecuentemente hacia un objeto al que la razón está lejos de conducir" (Althusser, 2004, pp. 70-71). Este gesto del Maquiavelo de Althusser no es solo filosófico, sino también ideológico. Pero acá la ideología maquiaveliana le da una primacía al conflicto y a la contingencia en un mundo que, en todo caso, es el mismo. En otras palabras: este gesto ideológico busca poner en evidencia que lo que es inmutable en el mundo es la tendencia a su propia transformación. En esa medida, se puede decir que desde el instante en el que un desposeído reclama el derecho a hacerse cargo de los asuntos comunes, se inicia, en el mundo occidental, la lucha de clases que, a juicio de Maquiavelo, se puede comprender, inicialmente, a través de su teoría de los ciclos de las formas de gobierno (que toma prestada de Polibio). Recordemos que Maquiavelo en los Discursos, específicamente en el segundo libro, aduce que todo ciclo inicia cuando un pueblo elige al mejor para que lo gobierne, instaurando así una monarquía. Sin embargo, la fundación de una monarquía degenera en una tiranía. A partir de ahí, los más virtuosos se rebelan y derrocan esa tiranía, fundando así la aristocracia. Pero de la misma manera que la monarquía degenera en tiranía; la aristocracia se transforma en oligarquía, provocando que esta vez sea el pueblo el que se rebele contra los oligarcas. Las nuevas generaciones de este gobierno democrático hacen que emerja la "licencia". Después de la licencia, el pueblo se subleva y busca un nuevo amo. Por lo tanto, el círculo se cierra (Discursos, § 2). Este conflicto cíclico causa desconcierto en Maquiavelo, sin embargo, su propuesta no se asemeja a la del republicanismo convencional. Maquiavelo no busca negar el conflicto que emerge con la lucha de clases, tratando de abrir el siguiente interrogante: ¿Es posible elaborar una teoría republicana que prolongue y haga durable la práctica democrática y, por lo tanto, la lucha de clases?; ¿es posible pensar en una república que le otorgue al pueblo las herramientas para la desobediencia, sin que este tenga que recurrir a prácticas mucho más extremas como la secesión plebeya o la práctica revolucionaria?; ¿hay alguna manera de negar el eterno ciclo de las revoluciones y de las tiranías sin traicionar a los sujetos que desencadenan el ciclo de los conflictos?; ¿es posible pensar en un republicanismo democrático?

La lectura de Althusser del legado maquiaveliano nos ayuda a esclarecer esas preguntas. Para el Maquiavelo de Althusser, todas las formas de gobierno son malas. Unas porque son arbitrarias y 
otras porque duran poco. En esa medida "el problema fundamental del Estado, que obsesiona a Maquiavelo en la revisión de la tipología clásica, es el de la duración del Estado. Maquiavelo se interesa por una sola forma de gobierno: la que permite al Estado durar" (Althusser, 2004, p. 75). Ahora bien, al pensador florentino le corresponde, en su utopía ideológico-teórica, reflexionar sobre las condiciones de posibilidad de un Estado que dure sin traicionar los acontecimientos democráticos. En otras palabras, Maquiavelo se traza la tarea de pensar en cierta estabilidad y prolongación de la práctica política en un mundo que permanece siempre igual y que no cesa de transformarse. En esa medida, me gustaría hacer especial énfasis en, al menos, tres condiciones de posibilidad para que se pueda prolongar el acontecimiento en la teoría maquiaveliana del príncipe nuevo que $\mathrm{Al}$ thusser lee en clave marxista.

La primera de ellas es la lucha de clases. Una sociedad que no haya puesto en cuestión la presunta necesidad de una sociedad dividida en clases o en castas no puede plantearse ni siquiera la posibilidad de pensar en una república democrática. Ahora bien, siguiendo la perspectiva de Althusser, un índice que permite la identificación de la lucha de clases en una sociedad es la existencia de la filosofía. Recordemos la famosa definición de Althusser de la filosofía como lucha de clases en la teoría (Althusser, 2011, p. 35), pero maticémosla de la siguiente manera: toda lucha de clases es en realidad una lucha por otorgar inteligibilidad al mundo. En esta lucha se enfrentan formas de comprender la realidad desde el punto de vista de las clases dominantes o desde el punto de vista de las clases subalternas. Llamaremos a este tipo de sociedades, sociedades políticas. En ellas los conflictos no son intersubjetivos, sino entre clases, entre formas de comprender el mundo que tienen consecuencias explícitas en términos de quienes mandan y cómo se gobierna una sociedad. Por esa razón, el conflicto político no es entre conciencias incondicionadas que comparten su punto de vista haciendo que el mundo adquiera más determinaciones; sino que es el conflicto que pone en cuestión los cimientos de una realidad compartida.

La segunda condición de posibilidad para la realización de una república democrática es la Revolución, es decir, el acontecimiento que detiene el tiempo de la dominación de los grandes. En esa medida, una sociedad que ha atravesado por un momento revolucionario se da cuando los pobres, los proletarios y las proletarias deciden no obedecer y, además, detienen los aparatos ideológicos de la dominación de clase. Esta situación plantea, a juicio Althusser, la posibilidad de fundar un cuerpo político y, por lo tanto, un aparato jurídico que permitiría estabilizar los ciclos de la lucha de clases. Acá entra a jugar la forma en la que Arendt conceptualiza el derecho positivo. Recordemos que para la pensadora alemana las leyes positivas son "concebidas principalmente como factores estabilizadores de los cambiantes movimientos de los seres humanos" (Arendt, 2009, p. 621). La Revolución es entonces un momento, violento o no, en el que los pobres de una sociedad instituyen un tiempo heterocrónico en el que se suspende la tempestividad del tiempo histórico del progreso. El tiempo de la Revolución se ubica en un estado intermedio entre un "ya no más" y un "todavía no" y, continuando con la perspectiva de Arendt, podríamos decir que la Revolución nos arroja ante un escenario que antes estaba consagrado a la especulación o al pensamiento sobre procedencia de todo lo existente. Por esa razón, en el momento revolucionario, la experimentación del pensamiento aparece ante los ojos de todos los seres humanos (Arendt, 2013, pp. 338339). Esto nos permite decir que la Revolución deshace, de una manera radical, la correspondencia entre la ley y la ley; entre la justicia y la justicia; entre el logos y el logos. En otras palabras, el momento revolucionario distorsiona el mundo de la mistificación ideológica que hace corresponder a las palabras con las cosas, que es a su vez el fundamento del orden del mundo y, por lo tanto, de las jerarquías sociales.

La tercera condición de posibilidad de la prolongación de la democracia es la fundación de una república democrática. Esta es precisamente la intención de Maquiavelo con su teoría del Príncipe Nuevo. Para poner en evidencia la lectura de Althusser de esta teoría, es necesario que tomemos muy al pie de la letra la obra de Maquiavelo. En esa medida no resulta plausible la lectura que hace Rousseau de este libro del florentino. Recordemos cómo en El Contrato Social se dice que "fingiendo dar lecciones a los reyes, las ha dado y muy grandes a los pueblos. El Príncipe de Maquiavelo es el libro de los republicanos" (El contrato social, p. 140). Althusser está dispuesto a mostrar que efectivamente El Príncipe es un libro de los republicanos, sin embargo, el énfasis debe ser puesto no tanto en la forma de gobierno republicana, sino más bien en la figura del fundador de un Estado que logra prolongar el acontecimiento revolucionario. Pensemos en la figura del repre- 
sentante obrero que, en ejercicio colectivo de la huelga, ha logrado transformarse en un negociador al disputar las condiciones para el regreso de las actividades con su patrón. Esta persona no es una simple representante. Esta persona es un sujeto político, que en su soledad puede hacer que la huelga se prolongue más allá de ella misma. Las esperanzas de un movimiento obrero son puestas en una persona, en un príncipe nuevo cuya tarea consiste en producir un verdadero Estado popular. Ahora bien, para que el acontecimiento se prolongue y se funde un nuevo orden del tiempo, que desgarre la evidencia del tiempo del progreso, esa soledad debe ser abandonada. Y tal abandono se produce en el instante en el que de dicha negociación emergen no tanto favores, compensaciones y prebendas para que las personas vuelvan a su lugar de trabajo, como leyes en el sentido político del término. Para explicar el carácter político de las leyes, Althusser hace uso de la metáfora de lo que él llama 'enraizamiento' del Príncipe en el pueblo:

Es el momento concreto, orgánico, bien de la penetración de las leyes promulgadas en las clases sociales antagonistas, o de la producción de las leyes mediante la lucha del pueblo contra los grandes. Este enraizamiento del poder del Príncipe en el pueblo mediante el juego de las leyes es la condición absoluta de la duración del Estado y de su potencia, es decir, de su capacidad de crecer (Althusser, 2004, p. 97).

Estas palabras de Althusser permiten poner en evidencia que la fundación de un orden auténticamente jurídico-político ocurre cuando la reforma que logra el representante obrero de nuestro ejemplo transforma, efectivamente, el campo de experiencia de los trabajadores y las trabajadoras. Este es precisamente el sentido que Walter Benjamin le da a la huelga general proletaria (proletarischer Generalstreik). Recordemos que Benjamin nos dice que esta huelga "no se dispone a reanudar la actividad laboral luego de concesiones superficiales y vagas modificaciones de las condiciones laborales, sino que resuelve retomar un trabajo totalmente distinto al anterior, uno no impuesto por el derecho" (Benjamin, 2009, p. 51). En esa medi$\mathrm{da}$, la soledad del fundador o de la fundadora de la república democrática es abandonada cuando sus demandas se vuelven leyes que, a su vez, multiplican otras demandas y otras voces no escuchadas, abriendo así el porvenir hacia una vida totalmente distinta de la anterior. Este tipo de leyes, al ser producidas mediante la lucha del pueblo contra los grandes, se sumergen en el antagonismo de clase haciendo más evidente las razones del conflicto político de los seres humanos. En otras palabras, las leyes que emergen del antagonismo de clase no tienen como objetivo la unificación de visiones de mundo, como tampoco la construcción de una comunidad cada vez más consensual que acoge a todas las diferencias en una sociedad liberal que no se extraña ni se escandaliza por las diferencias. El objetivo de este tipo de leyes es, más bien, la multiplicación de los conflictos y de las condiciones de posibilidad para que Príncipes nuevos emerjan a lo largo y ancho de nuestras sociedades con nuevos antagonismos. Tenemos entonces que la tercera condición de posibilidad de una república democrática es la transformación del acontecimiento en duración. Esto se logra cuando, en el medio de un antagonismo de clase, emergen momentos en los que los representantes de los movimientos populares logran hacer efectivas sus luchas, haciendo promulgar leyes que, ciertamente no fundan ni realizan plenamente la democracia, sino que permiten que los conflictos de clase emerjan con más frecuencia y que las mistificaciones ideológicas dejen de primar en nuestra vida en común. La soledad del príncipe nuevo, es decir, la soledad de quienes el azar les ha hecho estar sentados negociando acuerdos con los Grandes de una sociedad constituye una interrupción de la tempestividad del tiempo de la dominación, que puede llegar a manifestarse en una mera ley, en una mera prohibición de la sobre-explotación de la fuerza de trabajo; en el otorgamiento de derechos a un río; o en la garantía de una educación universal y gratuita. Estas leyes no son prebendas, ni bienes que obtiene el pueblo para ascender socialmente; son inscripciones de luchas democráticas que aseguran las condiciones de posibilidad para nuevas luchas políticas y, por lo tanto, de nuevos antagonismos de clase.

Ciertamente esta transformación del acontecimiento en duración no es una hiper-politización del mundo. No significa que todo ciudadano esté obligado a participar en los antagonismos de clase y de reivindicar derechos en movimientos populares. La libertad que se instituye cuando se promulgan leyes de carácter político permiten, al menos, dos formas de vivir-juntos democráticas. Una es la democracia de la vida política. Esta forma de vivir juntos garantiza que el pueblo tenga más herramientas jurídicas y culturales para luchar en contra de los grandes. La otra es la democracia de la vida cotidiana. Acá no tenemos movimientos sociales ni representantes luchando en una mesa de negociación frente a oligarcas. Esta forma de 
vida democrática permite que las personas hagan sus actividades cotidianas con cierta conciencia de la contingencia que condiciona sus propias vidas. Con esto quiero decir que la democracia de la vida cotidiana es una configuración ideológico-crítica que nos hace caer en la cuenta de que la historia no está condicionada por ninguna necesidad histórica, sino por un conjunto infinito de accidentes que fundan un mundo en común. Somos campesinos, zapateras y zapateros, docentes, trabajamos la madera, nos dedicamos a las labores del cuidado, nos ha tocado ser coteros, mandaderos, trabajadoras y trabajadores sexuales, padres, madres; nos ha ido muy bien haciendo negocios y también nos hemos arruinado, sin embargo lo que somos y lo que hacemos no está inscrito en ninguna necesidad histórica, religiosa o genética, sino que es el resultado de lo que Althusser llegó a llamar "materialismo del encuentro" o "materialismo aleatorio", el mero azar que hace que nos encontremos con una identidad, con un rol o con una función en la sociedad. Ahora bien, desde la perspectiva que he intentado desarrollar en este texto, para adquirir esta conciencia necesitamos de la seguridad que brinda la república democrática, pues sus leyes que emergen de la lucha de clases nos permiten "tener el tiempo y el espacio" para pensar en que existe una posibilidad latente de dejar de hacer lo que hacemos, o, mejor aún, de, como dice Bartelby el escribiente, decirle a nuestro destino "preferiría no hacerlo". Hoy no existe ninguna república democrática que nos permita pensar que preferiríamos no ser lo que somos. Pero creo que este sería la utopía que nos ofrece la confluencia entre el pensamiento republicano y el pensamiento democrático que he intentado discutir.

\section{CONCLUSIÓN}

Los anteriores párrafos buscaron problematizar el gesto ideológico que fundamenta la oposición entre idealizaciones republicanas y prácticas democráticas. Siguiendo los postulados de Rancière y Althusser, señalé que la filosofía política es una práctica ideológica que busca mostrar la necesidad de otorgar orden a nuestra experiencia compartida, siguiendo la idea de la mistificación, es decir, la idea de que el fundamento de todo orden de sentido es la necesidad.

En oposición a esta ideología mistificadora, desarrollé una aproximación a la práctica política que actualiza la ausencia de fundamento del orden social. Ahora bien, siguiendo el pensamiento político de Althusser en Maquiavelo y nosotros, señalé algunas indicaciones para contemplar la posibilidad de prolongar el momento emancipatorio con la instauración de una república democrática que permitiría, a su vez, que nuestras prácticas cotidianas se encuentren no tanto con la necesidad, sino con la contingencia que fundamenta todo orden social. La utopía, o mejor aún, la heterotopía maquiaveliana busca hacernos ver una tradición oculta que tiene como horizonte la prolongación de una libertad política que busca abrir la vida común a la felicidad que trae consigo la posibilidad latente de dejar de ser lo que somos, de dejar de obedecer las condiciones que median nuestras decisiones.

\section{BIBLIOGRAFÍA}

Abensour, M. La démocratie contre l'État. Paris: Le Félin Poche, 1997.

Althusser, L. Maquiavelo y nosotros. Madrid: Akal, 2004.

Althusser, L. Machiavel en nous. Paris: Tallandier, 2009.

Althusser, L. Sur la réproduction. Paris: Presses Universitaires de France, 2011.

Althusser, L. Initiation à la philosophie pour les non-philosophes. Paris: Presses Universitaires de France, 2014.

Althusser, L. Etre marxiste en philosophie. Paris : Presses Universitaires de France, 2015.

Arendt, H. Los orígenes del totalitarismo. Madrid: alianza editorial, 2009.

Arendt, H. Sobre la revolución. Madrid: Alianza, 2013.

Benjamin, W. "Para una crítica de la violencia" En: Estética y política. Buenos Aires: La cuarenta, 2009.

Fajardo, C. "Lo común en el primer volumen de El Capital de Karl Marx". Izquierdas, 47, 30053023, 2020. http://doi.org/10.4067/s0718504920200001002142

Fajardo, C. "Mystified Alienation: A discussion between Marx, Foucault and Federici”. TripleC, 19 (2), 287300, 2021. https://doi.org/10.31269/triplec.v19i2.1277

Habermas, J. Facticidad y validez. Madrid: Trotta, 2007.

Kant, E. Crítica de la razón pura. México: Fondo de Cultura Económica, 2011.

Maquiavelo, N. Discursos sobre la primera década de Tito Livio. Madrid: Akal, 2016.

Marx, Karl. "Das Kapital, Kritik der politischen Ökonomie" En Gesamtausgabe, de Karl Marx. Berlin: Dietz Verlag, 1987.

Marx, K. La ideología alemana. Buenos Aires: Losada, 2010. 
Marx, K. El capital. México: Siglo XII Editores, 2017.

Merleau-Ponty, M. "Les aventures de la dialectique" En: Oeuvres. Paris: Gallimard, 2014.

Mouffe, C. Agonística: pensar el mundo políticamente. Buenos Aires: Fondo de Cultura Económica, 2014.

Paredes, D. "La impureza de la política". En: A la sombra de lo político. Bogotá: Universidad de los Andes, 2014.

Pettit, P. Republicanism: a theory of freedom and government. New York: Oxford University Press, 1999.

Pocock, J. G A. The Machiavellian Moment: Florentine Political Thought and the Atlantic Republican Tradition. New Jersey: Princeton University Press, 2003.
Rancière, J. La mésentente. París: Galilée, 1995.

Rancière, J. El odio a la democracia. Buenos Aires: Amorrortu, 2006.

Rancière, J. El filósofo y sus pobres. Buenos Aires: Traficantes de sueños, 2014.

Rousseau, J, J. El contrato Social. Madrid: Akal, 2018.

Schmitt, C. "Teología política I". En: Carl Schmitt, teólogo de la política. México: Fondo de Cultura Económica, 2004.

Skinner, Q. El nacimiento del Estado. Buenos Aires: Editorial Gorla, 2003.

Žižek, S. El sublime objeto de la ideología. México: Siglo XII editores, 2018. 